\title{
Economic Burden of Osteoporotic Patients with Fracture: Effect of Treatment With or Without Calcium/Vitamin D Supplements
}

This article was published in the following Dove Press journal: Nutrition and Dietary Supplements

\author{
Luca Degli Esposti \\ Stefania Saragoni' \\ Valentina Perrone' \\ Stefania Sella ${ }^{2}$ \\ Margherita Andretta ${ }^{3}$ \\ Maurizio Rossini (iD ${ }^{4}$ \\ Sandro Giannini ${ }^{2}$ \\ 'CliCon S.r.l. Health, Economics \& \\ Outcomes Research, Ravenna, Italy; \\ ${ }^{2}$ Clinica Medica I, Department of \\ Medicine, University of Padova and \\ Regional Center for Osteoporosis, \\ Padova, Italy; ${ }^{3}$ UOC HTA, Azienda Zero, \\ Padova, Italy; ${ }^{4}$ Rheumatology Unit, \\ Azienda Ospedaliera Universitaria \\ Integrata di Verona and Regional Center \\ for Osteoporosis, Verona, Italy
}

Background: Fractures represent the most important complication of osteoporosis, in terms of loss of independency, chronic pain, increased risk of mortality, but also high healthcare costs.

Objective: To assess healthcare costs in an Italian cohort of osteoporotic patients with a fracture with and without specific osteoporosis treatment and supplementation with calcium/vitamin D.

Methods: This retrospective observational study used data from administrative databases of five Local Health Units in Italy. Patients $\geq 50$ years of age and hospitalized for vertebral or hip fracture occurring from 01/01/2011 to 31/12/2015 were included. Patients were then classified as "untreated" and "treated" if they had been treated or not with drugs for fracture prevention after the index fracture. We also identified subjects that were only treated with drugs for fracture prevention, "osteoporosis drug only" group, compared to the "osteoporosis drug plus calcium/vitamin D" group, in which calcium and/or vitamin D were also in combination. Healthcare cost analysis included drug expenditure, hospitalization costs (excluding costs related to the hospitalization for the index fracture) and outpatient service costs.

Results: Three thousand four hundred and seventy-five patients were included in the present study, most of whom (58.5\%) had received specific osteoporosis treatment after index fracture. Among treated patients, the vast majority (83.6\%) received supplementation with calcium/vitamin D. Mean annual healthcare cost per patient was $€ 9,289.85$ in the untreated group and $€ 4,428.26$ for treated subjects $(p<0.001$ ); mean annual healthcare cost for the osteoporosis drug-only group was higher compared to the osteoporosis drug plus calcium/ vitamin D group $(€ 5,976.88$ vs $€ 4,124.74$, respectively, $\mathrm{p}<0.001)$. Hospitalization costs accounted for the majority of total costs in all groups of patients.

Conclusion: Healthcare costs in patients with osteoporotic fractures were significantly lower in those receiving osteoporosis treatment compared to untreated patients with even lower costs observed in patients that were also receiving calcium/vitamin D supplements.

Keywords: healthcare costs, calcium/vitamin D supplementation, osteoporosis, fracture, hospitalization

\section{Introduction}

Osteoporosis is a systemic skeletal disorder characterized by decreased bone mass and qualitative alterations of the bone micro-architecture associated with increased fracture risk. ${ }^{1}$ Osteoporosis is often asymptomatic and frequently diagnosed after the first fracture, which represents the clinical manifestation of the disease. ${ }^{1}$ In 2010, it was estimated that about 22 million women and 5.6 million of men aged over 50 in Europe were diagnosed with osteoporosis. ${ }^{2}$ In Italy, osteoporosis affects about 5 million subjects, of whom $80 \%$ is represented by post-menopausal women. ${ }^{3}$
Correspondence: Luca Degli Esposti CliCon S.r.l. Health, Economics \&

Outcomes Research, Via Salara, 36,

Ravenna 48121 , Italy

Tel +39054438393

Fax +390544212699

Email luca.degliesposti@clicon.it 
The prevalence of osteoporosis is constantly growing, as well as the number of associated fragility fractures. In particular, an increase in osteoporosis diagnosis of $23 \%$ in Europe and $25 \%$ in Italy between 2010 and 2020 was estimated. $^{2}$

Osteoporotic fractures represent the major complication of osteoporosis, both in terms of limitation of ambulation, chronic pain, loss of independency, decreased quality of life and in terms of increased risk of mortality: the risk of mortality being $15-20 \%$ in the first year after hip fracture. ${ }^{2}$ Moreover, fractures are related to a high healthcare expenditure, particularly for hospitalization costs. $^{2,4-6}$ In 2017 in Italy 560,000 new fragility fractures occurred, with the cost for the Italian national health care system of $€ 9.4$ billion. As the number of osteoporotic fractures is estimated to increase in subsequent years due to demographic changes, these costs are also projected to increase by $26 \%$ (reaching $€ 11.9$ billion) by $2030 .^{4}$ According to the results of the BLOCK study ${ }^{6}$ among Italian osteoporotic female patients, mean annual healthcare costs of patients with an incident fracture were found to be four times higher when compared to patients with no fractures. Moreover, the analysis of the components of the healthcare costs for these patients revealed that hospitalization costs accounted for almost the total costs, whereas the effect of pharmacological treatment and outpatient specialist services costs was almost negligible. ${ }^{6}$ Lastly, surgical management of fractures appeared to comprise $80 \%$ of the total hospitalizations due to osteoporosis. ${ }^{5}$

The primary endocrine factors involved in the development of osteoporosis are parathyroid hormone (PTH), vitamin $\mathrm{D}$, calcitonin, and estrogen and as such, treatments are mainly focused on modifying these factors. Current treatment options include bisphosphonates, hormones, monoclonal antibodies, and bone growth agents as well as calcium and vitamin D supplementation. ${ }^{7}$

Bisphosphonates (eg alendronate and zoledronic acid) are recommended as first-line treatments for post-menopausal osteoporosis. ${ }^{8}$ They block the action of bone cells (osteoclasts), thereby inhibiting bone resorption. ${ }^{9,10}$

Hormones, such as estrogen, can play a role in osteoporosis prevention and treatment. ${ }^{11}$ Estrogen can also block bone resorption by interacting with tissue-specific receptors, estrogen receptor $\alpha$ and estrogen receptor $\beta$, to increase osteoclast apoptosis. However, concern exists regarding the side effects and risk of cancer.
More recently, monoclonal antibody medications such as denosumab have become available. Denosumab is a fully human monoclonal antibody and inhibits bone resorption by binding to the receptor activator of nuclear factor-kappa $\mathrm{B}$ ligand, thereby decreasing the differentiation of osteoclasts. ${ }^{12}$

Teriparatide, a "bone-building medication" is identical to a portion of human PTH and intermittent use activates osteoblasts more than osteoclasts, which leads to an overall increase in bone. It is currently the only approved anabolic agent for the treatment of osteoporosis that stimulates osteoblastic bone formation to improve bone quality and bone mass. ${ }^{13}$

Supplementation with calcium and vitamin D plays an important role in the management of osteoporosis. Vitamin $\mathrm{D}$ increases the plasma levels of calcium and phosphorus, regulates osteoblast and osteoclast activity, and combats PTH hypersecretion, promoting bone formation and preventing/treating osteoporosis. ${ }^{14-18}$

In previous studies, osteoporosis drugs were not only shown to be effective in preventing the incidence of vertebral and non-vertebral fractures, ${ }^{19-21}$ but also to be cost-effective in osteoporotic women compared to no treatment, especially among those who had already experienced a fracture. ${ }^{22}$

In addition to osteoporosis treatment, the essential role of calcium and vitamin D supplementation was largely acknowledged ${ }^{18}$ and approved by the Italian Medicines Agency in patients at risk of fragility fractures or subsequent fractures starting osteoporosis treatment. ${ }^{23}$ Unfortunately, many osteoporosis patients do not receive specific treatment after a fracture, showing poor adherence to national guidelines, even if osteoporosis drug treatment (and to a greater extent in combination with calcium/vitamin D) is associated with a lower risk of both re-fracture and all-cause mortality. ${ }^{24}$

The aim of this study was to assess healthcare costs in an Italian cohort of osteoporotic patients with a fracture, focusing on the presence of specific osteoporosis treatment and supplementation with calcium/vitamin D.

\section{Methods}

\section{Source of Data}

Data from the present retrospective observational study were extracted from administrative databases (DBs) of the following 5 Italian Local Health Units (LHUs), distributed across the National territory: Napoli 3 Sud, Pescara, Udine, Verona and Frosinone. The study design, data extraction and information on patient characteristics have been previously described in 
detail. $^{24}$ Briefly, the following databases were assessed: Beneficiary DBs, Hospitalization DBs, Pharmaceuticals DBs and Payment Exemption DBs. All patients were identified in DBs using an anonymous code and data were extracted by the staff of the LHUs and their DBs were anonymized according to the Legislative Decree 196/03. Results derived from all analyses were produced as aggregated summaries which were not possible to link directly or indirectly to individual patients. The use of encrypted retrospective information did not require informed consent. Local ethics committee of all LHUs involved in the study was notified, according to Italian law. ${ }^{25}$

\section{Cohort Definition}

Osteoporotic patients aged $\geq 50$ years hospitalized for vertebral or hip fracture occurring between 01/01/2011 and $31 / 12 / 2015$ were included. Identifiers (ICD-9-CM and ATC codes) used to define the patient cohort are summarized in Table 1. The following fractures occurring in the primary discharge diagnosis field were identified for inclusion: vertebral fractures with or without spinal cord injury and hip fractures. To exclude patients with a hospital readmission (due to follow-up visits after fracture) only subjects discharged for hip fractures associated with

Table I Inclusion/Exclusion Criteria for Cohort Definition and Outcome Measures Considered

\begin{tabular}{|c|c|}
\hline Characteristic & Disease and Drug Codes \\
\hline Inclusion Criteria & \\
\hline $\begin{array}{l}\text { Patient/disease characteristics } \\
\text { Vertebral fractures, with/without spinal cord injury } \\
\text { Hip fractures } \\
\text { Subjects discharged for hip fractures associated with } \\
\text { a concomitant surgical procedure } \\
\text { One hospitalization discharge diagnosis of osteoporosis }\end{array}$ & $\begin{array}{l}\text { ICD-9-CM codes } 805 \text { and } 806 \\
\text { ICD-9-CM code } 820 \\
\text { ICD-9-CM codes } 79.00,79.05,79.10,79.15,79.20,79.25,79.30,79.35,79.40 \text {, } \\
79.45,79.50,79.55 ; 81.51,81.52 \\
\text { ICD-9-CM code } 733.0\end{array}$ \\
\hline $\begin{array}{l}\text { Anti-fracture drugs } \\
\text { Bisphosphonates* } \\
\text { Plus vitamin D } \\
\text { Plus denosumab and strontium ranelate } \\
\text { Plus teriparatide and parathyroid hormones } \\
\text { Plus calcitonin } \\
\text { Plus selective estrogen receptor modulators } \\
\text { Calcium and vitamin D }\end{array}$ & $\begin{array}{l}\text { ATC M05BA, excluding M05BA08 } \\
\text { ATC M05BB03 } \\
\text { ATC M05BX } \\
\text { H05AA } \\
\text { H05BA } \\
\text { G03XC } \\
\text { ATC codes AI2AA, AI2AX, AIICC (excluding AIICC03 and AIICC04) }\end{array}$ \\
\hline Exclusion criteria & \\
\hline $\begin{array}{l}\text { Renal disease } \\
\text { Malignancies }\end{array}$ & $\begin{array}{l}\text { ICD-9-CM codes 584-585 or exemption code } 023 \\
\text { ICD-9-CM codes } 140-208 \text { or exemption code } 048\end{array}$ \\
\hline Follow-up variables & \\
\hline $\begin{array}{l}\text { Drugs } \\
\text { Corticosteroids for systemic use } \\
\text { Platelet aggregation inhibitors } \\
\text { Vitamin } \mathrm{K} \text { antagonists/Xa factor inhibitors } \\
\text { Analgesics } \\
\text { Anticonvulsants } \\
\text { Antipsychotics/anxiolytics } \\
\text { Proton pump inhibitors }\end{array}$ & $\begin{array}{l}\text { ATC } \mathrm{H} 02 \\
\text { ATC BOIAC } \\
\text { ATC BOIAA, BOIAE, BOIAF } \\
\text { ATC N02 } \\
\text { ATC N03 } \\
\text { ATC N05A, N05B } \\
\text { ATC A02BA }\end{array}$ \\
\hline $\begin{array}{l}\text { Incidence of re-fracture } \\
\text { Vertebral forms with and without spinal cord injury } \\
\text { Radius and ulna and hip fractures } \\
\text { With concomitant replacement procedure }\end{array}$ & $\begin{array}{l}\text { ICD-9-CM codes } 805,806 \\
I C D-9-C M \text { codes } 813 \text { and } 820 \\
79.00,79.05,79.10,79.15,79.20,79.25,79.30,79.35,79.40,79.45,79.50,79.55 \text {, } \\
81.51,81.52\end{array}$ \\
\hline
\end{tabular}

Notes: *Bisphosphonates were the only anti-fracture drug that could have been administered together with vitamin $D$ as a single tablet. All other drugs were administered separately as different tablets.

Abbreviations: ATC, Anatomical Therapeutic Chemical; ICD, International Classification of Diseases. 
a concomitant surgical procedure were included. All patients had at least one hospitalization discharge diagnosis of osteoporosis during the inclusion period.

Prescriptions of the following anti-fracture drugs following fracture were included: bisphosphonates and their combinations with vitamin $\mathrm{D}$, denosumab and strontium ranelate, teriparatide and parathyroid hormones, calcitonin, selective estrogen receptor modulators as well as calcium and vitamin D. Doses of different treatments administered are available as Supplementary Material Table 1).

Patients were defined as "treated" if they were receiving anti-fracture drugs alone or combined with calcium and vitamin D and defined as "untreated" when not taking anti-fracture drugs or calcium and vitamin $\mathrm{D}$ according to International guidelines. ${ }^{1}$ Index date was defined as the time a patient experienced the fracture resulting in hospitalization during the enrollment period. Patients with a fracture in the year prior to the index date were excluded. Patients presenting with renal diseases and malignancies occurring within the 2 years prior to the index date were also excluded. After inclusion, patients were followed for at least 1 year, from the index date to $31 / 12 / 2016$.

\section{Baseline Characteristics}

Over the 1-year pre-index period before the index date, patients were characterized by collecting their demographic data, comorbidities and drug use. Comorbidities were identified by discharge diagnosis codes (both primary and secondary, according to ICD-9-CM codes; Table 1) or the prescription of a specific disease-related drug (ie insulin for diabetes mellitus) when the diagnosis was not available. The following comorbidities were evaluated: hypertension, diabetes mellitus, dyslipidemia, ischemic heart disease, cardiac arrhythmias, heart failure, stroke, chronic obstructive pulmonary disease. Based on comorbidities, patients were also assigned the Charlson Comorbidity Index (CCI) score. $^{26}$ The CCI score was categorized as $\leq 1$ and $>1$. To exclude occasional therapies, the previous use of drugs required at least two reported prescriptions. Use of the following drugs in the 12 months prior to inclusion was evaluated: corticosteroids for systemic use, platelet aggregation inhibitors, vitamin $\mathrm{K}$ antagonists or Xa factor inhibitors, analgesics, anticonvulsants, antipsychotics or anxiolytics and proton pump inhibitors.

\section{Study Variables}

During the follow-up period, the incidence of re-fractures was analyzed. Study variables considered over the follow-up period according to ICD-9-CM codes are summarised in Table 1.
For re-fracture, we considered vertebral forms with and without spinal cord injury, radius and ulna and hip fractures with the concomitant replacement procedure. Moreover, adherence to osteoporosis treatment, with or without calcium and vitamin $\mathrm{D}$, was analyzed during follow-up by Medication Possession Ratio (MPR) and categorized as "adherent" (MPR $\geq 80 \%$ ), "partially adherent" (MPR=40-79\%) and "non-adherent" $(\mathrm{MPR}<40 \%)$. For each drug considered, the Defined Daily Dose was considered.

\section{Cost Analysis}

Costs for each single health resource used per patient were evaluated over the follow-up period, and based on the following resource consumption: hospitalization costrelated and unrelated to osteoporosis, determined using the diagnosis-related groups (DRGs) tariffs, and which includes costs of medical devices (ie prosthesis); drug cost, evaluated for those drugs reimbursed by the Italian NHS and using the INHS purchase price, and including related- and unrelated-osteoporosis treatments; outpatient specialist service costs, the cost of instrumental and laboratory tests according to Regional tariffs. Analysis of healthcare costs was performed by excluding costs of the index hospitalization (ie hospitalization for the first fracture). The healthcare cost analysis was undertaken with the perspective of the INHS. Results are expressed as the mean annual healthcare costs per patient.

\section{Statistical Analysis}

Continuous data were presented as mean \pm standard deviation (SD) and categorical data as a percentage of patients. Univariate analyses ( $\chi^{2}$ test and Student's $t$-test) were used to compare baseline and clinical characteristics and healthcare costs among the cohorts of patients included in the study. Predictors of healthcare costs were identified using a multivariate regression model, including the following covariates: age, gender, co-morbidities, medication, type and adherence to osteoporotic treatment. A p-value of $<0.05$ was considered statistically significant. All statistical analyses were performed using STATA SE (Stata Corp LP, College Station, TX, USA), version 12.0. Data management was carried out using Microsoft SQL Server 2012.

\section{Results}

\section{Baseline Characteristics of Patients}

A total of 3475 patients were selected. After the hospitalization for the index fracture, more than half of the patients 
(58.5\%) were treated, whereas $41.5 \%$ did not receive osteoporosis treatment or calcium/vitamin D (Figure 1). Patient characteristics have previously been described in detail. ${ }^{24}$ Baseline and clinical characteristics of the study population and by type of treatment received are reported in Table 2.

Compared to treated patients, untreated patients were older ( $83.6 \pm 8.7$ vs $78.2 \pm 8.7$ years, $p<0.001$ ), had a slightly higher prevalence of comorbidities and use of drugs not related to osteoporosis. Patients of the treated cohort were more likely to have had osteoporosis treatment prior to the incident fracture as compared to untreated patients $(70.4 \%$ vs $36.8 \%, \mathrm{p}<0.001$ ).

Among treated patients, $16.4 \%$ received osteoporosis treatment only whereas the vast majority $(83.6 \%)$ received osteoporosis treatment in combination with calcium/vitamin D (Table 2). No differences were found between these two cohorts in terms of comorbidities; patients receiving calcium/vitamin D supplements were more likely to have had calcium/vitamin D before the fracture $(81.3 \%$ vs $45.3 \%, \mathrm{p}<0.001)$ and less likely to have had osteoporosis drugs $(67.7 \%$ vs $84.4 \%, \mathrm{p}<0.001)$ compared to osteoporosis drug only cohort.

\section{Re-Fracture and Treatment Adherence}

Over a mean follow-up period of $2.8 \pm 1.6$ years, 108 patients of the untreated cohort (incidence rate 41.2/1000 persons years) and 127 patients of the treated cohort (incidence rate 19.7/1000 persons years) experienced a re-fracture event. Among treated patients, the re-fracture event was observed in 43 patients of the cohort receiving osteoporosis drug only (incidence rate 48.8/1000 persons years) and 84 patients of the cohort receiving osteoporosis drugs with calcium/vitamin D (incidence rate 15.1/1000 persons years). Moreover, the proportion of patients adherent to treatment (MPR $\geq 80 \%$ ) during the follow-up period was higher in the osteoporosis drug with calcium/vitamin D group compared to osteoporosis treatment only group $(48.0 \%$ vs $29.7 \%$, respectively, $\mathrm{p}<0.001)$.

\section{Cost Analysis}

The annual healthcare costs evaluated over the followup period and reported as the mean annual cost per patient are presented in Table 3. Total costs for the untreated cohort were higher compared to the treated cohort ( $€ 9,289.85$ vs $€ 4,428.26$, respectively, $\mathrm{p}<0.001)$.

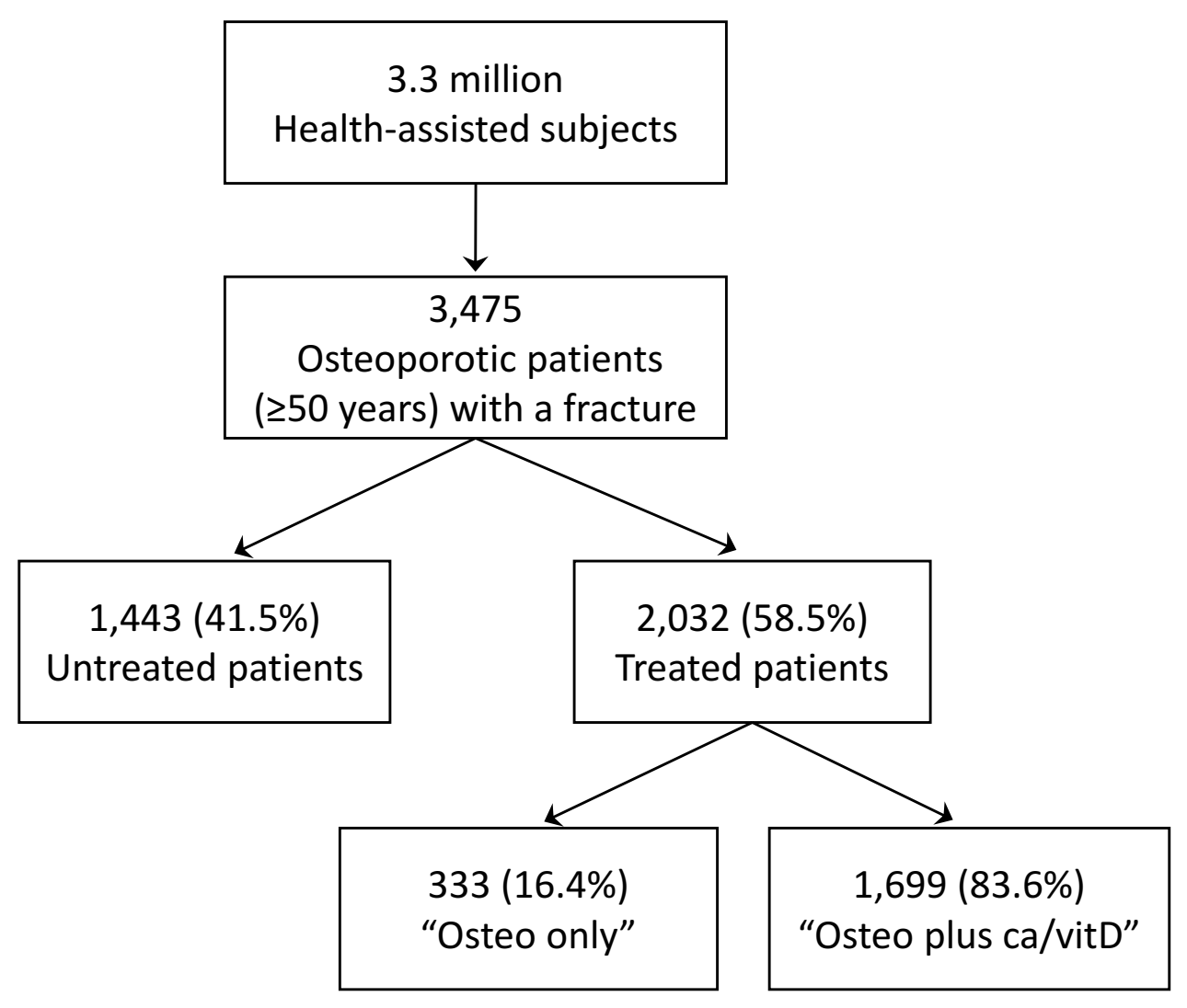

Figure I Patient disposition. 
Table 2 Baseline Characteristics of the Study Population According to the Treatment Prescribed

\begin{tabular}{|c|c|c|c|c|c|c|}
\hline & \multirow{2}{*}{$\begin{array}{l}\text { Untreated } \\
\text { Cohort } \\
(N=\mid 443)\end{array}$} & \multirow{2}{*}{$\begin{array}{l}\text { Treated } \\
\text { Cohort } \\
(\mathrm{N}=2032)\end{array}$} & \multirow[t]{2}{*}{ p-value } & \multicolumn{2}{|c|}{ Treated Cohort } & \multirow[t]{2}{*}{ p-value } \\
\hline & & & & $\begin{array}{l}\text { Osteoporosis } \\
\text { Drug Only } \\
(\mathbf{N}=333)\end{array}$ & $\begin{array}{l}\text { Osteoporosis } \\
\text { Drug + Ca/VitD } \\
(N=1699)\end{array}$ & \\
\hline Age, years mean $( \pm S D)$ & $83.6(8.7)$ & $78.2(8.7)$ & $<0.001$ & $81.3( \pm 8.0)$ & $77.6( \pm 8.7)$ & $<0.001$ \\
\hline Female, \% & 83.0 & 94.1 & $<0.001$ & 91.6 & 94.6 & 0.034 \\
\hline \multicolumn{7}{|l|}{$\mathrm{CCl}$ score, \% } \\
\hline$\leq 1$ & 71.7 & 72.2 & 0.704 & 70.0 & 72.7 & 0.311 \\
\hline$>1$ & 28.3 & 27.8 & & 30.0 & 27.3 & \\
\hline \multicolumn{7}{|l|}{ Comorbidities, \% } \\
\hline Hypertension & 75.1 & 71.0 & 0.008 & 75.4 & 70.2 & 0.055 \\
\hline Diabetes & 18.4 & 13.4 & $<0.001$ & 15.3 & 13.0 & 0.258 \\
\hline Dyslipidemia & 23.1 & 24.9 & 0.228 & 21.6 & 25.5 & 0.136 \\
\hline Ischemic heart failure & 4.6 & 2.8 & 0.003 & 2.4 & 2.8 & 0.667 \\
\hline Cardiac dysrhythmias & 11.5 & 8.8 & 0.009 & 11.4 & 8.3 & 0.067 \\
\hline Heart failure & 3.4 & 1.5 & $<0.001$ & 2.4 & 1.3 & 0.125 \\
\hline Stroke & 6.5 & 3.2 & $<0.001$ & 4.2 & 3.1 & 0.282 \\
\hline COPD & 13.4 & 12.3 & 0.321 & 12.3 & 12.3 & 0.996 \\
\hline \multicolumn{7}{|l|}{ Previous osteoporosis treatment, \% } \\
\hline Osteoporosis drugs & 36.8 & 70.4 & $<0.001$ & 84.4 & 67.7 & $<0.001$ \\
\hline Calcium/Vitamin D & 78.3 & 75.4 & 0.045 & 45.3 & 81.3 & $<0.001$ \\
\hline \multicolumn{7}{|l|}{ Other drugs, $\%$} \\
\hline Corticosteroids for systemic use & 10.5 & 17.0 & $<0.001$ & 12.0 & 18.0 & 0.008 \\
\hline Platelet aggregation inhibitors & 40.3 & 34.0 & $<0.001$ & 36.9 & 33.4 & 0.209 \\
\hline Vitamin $\mathrm{K}$ antagonists/ $\mathrm{Xa}$ factor inhibitors & 10.6 & 6.4 & $<0.001$ & 9.0 & 5.9 & 0.033 \\
\hline Analgesics & 14.0 & 15.7 & 0.167 & 12.0 & 16.4 & 0.043 \\
\hline Anticonvulsants & 6.3 & 7.5 & 0.181 & 7.5 & 7.5 & 0.984 \\
\hline Antipsychotics/anxiolytics & 6.7 & 3.2 & $<0.001$ & 4.5 & 3.0 & 0.157 \\
\hline PPI & 48.9 & 52.0 & 0.066 & 48.9 & 52.6 & 0.220 \\
\hline
\end{tabular}

Abbreviations: SD, Standard Deviation; CCl, Charlson Comorbidity Index; COPD, Chronic Obstructive Pulmonary Disease; PPI, Proton Pump Inhibitor.

Analysis of each item costs revealed that the higher costs were attributed to hospitalizations: $84 \%$ and $59.3 \%$ ( $€ 7,801.74$ for untreated cohort vs $€ 2,627.77$ for treated cohort, respectively, $\mathrm{p}<0.001$ ), for untreated and treated cohorts, respectively. As expected, drug costs were higher in the treated cohort compared to the untreated group $(€ 1,159.55$ vs $€ 677.18$, respectively, $\mathrm{p}<0.001$ ).

Among treated patients, total annual cost (excluding costs related to hospitalization index) for patients with osteoporosis drugs only was higher compared to those receiving osteoporosis drugs with calcium/vitamin $\mathrm{D}(€ 5,976.88$ vs $€$ 4,124.74, respectively, $\mathrm{p}<0.001$, Table 3). Hospitalization costs accounted for $73.7 \%$ and $55.2 \%$ of the total cost for osteoporosis drug only cohort and osteoporosis drug with calcium/vitamin D cohort, respectively. No differences among the two cohorts of patients were observed for drug costs $(€ 1,056.95$ osteoporosis drug only vs $€ 1,179.66$ osteoporosis drug with calcium/vitamin $\mathrm{D}, \mathrm{p}=0.196$ ).

\section{Predictors of Healthcare Costs}

Results from the multivariate analysis of total annual healthcare costs (Table 4) revealed that supplementation with calcium/vitamin D emerged as a predictor of cost reduction $(\beta$-coefficient $=-€ 1,296.91,95 \%$ CI: $-€ 2,155.90-€ 437.93$, $\mathrm{p}=0.003)$, on the contrary, age $(\beta=€ 33.66,95 \%$ CI: $€ 5.13$ $€ 62.19, \mathrm{p}=0.021)$, use of vitamin $\mathrm{K}$ antagonists/Xa factor inhibitors $(\beta=€ 1,857.97,95 \%$ CI: $€ 147.27 € 3,598.67$, $\mathrm{p}=0.033)$ and analgesics $(\beta=€ 1,364.62,95 \%$ CI: $€ 422.57$ $€ 2,306.67, \mathrm{p}=0.005)$ were related to increased costs. Furthermore, adherence to osteoporosis treatment (with or without calcium/vitamin D) was shown to be a factor related to cost reduction, even if this result did not attain statistical significance (Table 4). 
Table 3 Mean Annual Healthcare Cost (Excluding Costs Related to Index Hospitalization) per Patients Over the Follow-Up Period

\begin{tabular}{|c|c|c|c|c|c|c|}
\hline \multirow[t]{2}{*}{ Cost Items } & \multirow{2}{*}{$\begin{array}{l}\text { Untreated Cohort } \\
(N=1443)\end{array}$} & \multirow{2}{*}{$\begin{array}{l}\text { Treated Cohort } \\
(\mathrm{N}=\mathbf{2 0 3 2})\end{array}$} & \multirow[t]{2}{*}{ p-value } & \multicolumn{3}{|l|}{ Treated Cohort } \\
\hline & & & & $\begin{array}{l}\text { Osteoporosis Drug } \\
\text { Only }(\mathrm{N}=\mathbf{3 3 3})\end{array}$ & $\begin{array}{l}\text { Osteoporosis Drug + } \\
\mathrm{Ca} / \text { VitD } \\
(\mathrm{N}=1699)\end{array}$ & p-value \\
\hline $\begin{array}{l}\text { Drugs (mean } \pm S D \text { ) } \\
\text { Median } \\
\text { Min-max }\end{array}$ & $\begin{array}{l}677.18( \pm 1,322.65) \\
319.44 \\
0.00-37,227.00\end{array}$ & $\begin{array}{l}1,159.55( \pm 1,585.58) \\
760.795 \\
0.00-28,720.70\end{array}$ & $<0.001$ & $\begin{array}{l}1,056.95( \pm 1,386.44) \\
727.45 \\
0.00-14,588.25\end{array}$ & $\begin{array}{l}1,179.66( \pm 1,621.36) \\
766.04 \\
15.44-28,720.70\end{array}$ & 0.196 \\
\hline $\begin{array}{l}\text { Hospitalizations (mean } \pm \mathrm{SD} \text { ) } \\
\text { Median } \\
\text { Min-max }\end{array}$ & $\begin{array}{l}7,801.74( \pm 25,380.60) \\
I, 431.58 \\
0.00-657,400.00\end{array}$ & $\begin{array}{l}2,627.77( \pm 6,212.82) \\
806.37 \\
0.00-128,988.80\end{array}$ & $<0.001$ & $\begin{array}{l}4,407.92( \pm 10,615.14) \\
1,114.43 \\
0.00-128,988.80\end{array}$ & $\begin{array}{l}2,278.86( \pm 4,836.70) \\
783.25 \\
0.00-69,271.51\end{array}$ & $<0.001$ \\
\hline $\begin{array}{l}\text { Outpatient services (mean } \pm \text { SD) } \\
\text { Median } \\
\text { Min-max }\end{array}$ & $\begin{array}{l}810.93( \pm 4,601.38) \\
176.55 \\
0.00-124,456.10\end{array}$ & $\begin{array}{l}640.94( \pm 1,253.65) \\
281.28 \\
0.00-21,376.61\end{array}$ & 0.113 & $\begin{array}{l}512.01( \pm 1084.37) \\
178.97 \\
0.00-9991.07\end{array}$ & $\begin{array}{l}666.21( \pm \mid 282.99) \\
305.23 \\
0.00-21,376.61\end{array}$ & 0.040 \\
\hline $\begin{array}{l}\text { Total }(\text { mean } \pm \text { SD) } \\
\text { Median } \\
\text { Min-max }\end{array}$ & $\begin{array}{l}9,289.85( \pm 25,846.20) \\
2,713.52 \\
0.00-657,400.00\end{array}$ & $\begin{array}{l}4,428.26( \pm 6,770.90) \\
2,568.50 \\
29.66-132,152.40\end{array}$ & $<0.001$ & $\begin{array}{l}5,976.88( \pm 10,993.06) \\
2,506.35 \\
29.66-132,152.40\end{array}$ & $\begin{array}{l}4,124.74( \pm 5,535.78) \\
2,571.33 \\
32.88-70,004.80\end{array}$ & $<0.001$ \\
\hline
\end{tabular}

Note: Values expressed in Euro.

Abbreviation: SD, standard deviation.

\section{Discussion}

In the present study, we describe the relationship between osteoporosis-related drug prescription and healthcare costs, in the perspective of the Italian NHS, in a cohort of patients aged 50 years and over after an osteoporotic fracture. Healthcare costs in osteoporotic patients with a fracture were lower in the treated group compared to untreated ones, and even lower in patients also receiving supplementation with calcium/vitamin D. These findings also parallel an improvement in the risk of re-fracture and mortality that we have described in a separate publication. ${ }^{24}$ Briefly, over a 3-year period, the risk of subsequent fractures was $44.4 \%$ lower in treated patients compared to untreated ones $(\mathrm{HR}=0.56,95 \% \mathrm{CI}=0.42-0.74, \mathrm{p}<0.001)$ and $64.4 \%$ lower in those receiving calcium/vitamin D supplementation compared to osteoporosis treatment only $(\mathrm{HR}=0.36,95 \% \mathrm{CI}=0.24-0.53, \mathrm{p}<0.001)$. The risk of re-fracture was $77.2 \%$ lower in treated patients who were adherent to medication $(\mathrm{HR}=0.23,95 \% \mathrm{CI}=0.14-0.38$, $\mathrm{p}<0.001)$. Treated patients had $64 \%$ lower mortality risk over the follow-up compared to untreated ones ( $\mathrm{HR}=0.36,95 \%$ $\mathrm{CI}=0.31-0.42, \mathrm{p}<0.001) .{ }^{24}$ To the best of our knowledge, only one prior study has investigated economic outcomes among osteoporotic patients, ${ }^{27}$ showing that, compared to no treatment, supplementation with calcium/vitamin D was costeffective in a population of osteoporotic patients aged over 60 years. However, the objective of this study differs from ours: the study by Hiligsmann et $\mathrm{al}^{27}$ was a cost-effectiveness evaluation of the supplementation with calcium and vitamin D in elderly women and men with osteoporosis, presented in terms of incremental cost-effectiveness ratio based on the cost per quality-adjusted life-years; here we aimed to assess healthcare cost, and the cost of each item, in a population of osteoporotic patients after a first fracture event, according to the presence of specific osteoporosis treatment and calcium/ vitamin D supply.

Our results showed that mean healthcare costs, over a mean follow-up of 2.8 years, were higher in the untreated group of osteoporotic patients compared to treated ones ( $€ 9,289.85$ vs $€ 4,428.26$, respectively, $\mathrm{p}<0.001$ ), excluding costs related to the index hospitalization. Moreover, analyzing single item costs, mean hospitalization costs per patients were significantly higher in the untreated cohort compared to the treated cohort $(€ 7,801.74$ vs $€ 2,627.77$, respectively, $\mathrm{p}<0.001)$. This may be explained by the efficacy of osteoporosis treatment in preventing subsequent fractures, as also demonstrated by the observed decrease in the incidence of further fractures in treated compared to untreated subjects and as suggested by a previous review showing the costeffectiveness of osteoporosis drugs among postmenopausal women with prior vertebral fractures. ${ }^{28}$ However, as expected, drug costs were higher in the treated cohort $(€ 1,159.55)$ compared to untreated patients (€677.18, $\mathrm{p}<0.001)$. In the present study, the incidence of re-fracture during the follow-up period in the untreated group was higher compared to the treated group (41.21/1000 persons years vs $19.73 / 1000$ persons years, respectively). However, 
Table 4 Multivariate Analysis of Total Healthcare Cost, Excluding Costs Related to Hospitalization Index

\begin{tabular}{|c|c|c|c|c|}
\hline & $\beta$ & $95 \% \mathrm{Cl}$ & & p-value \\
\hline Age & 33.66 & 5.13 & 62.19 & 0.021 \\
\hline Gender & 877.35 & -291.57 & 2046.27 & 0.141 \\
\hline $\mathrm{CCl}$ score $>1$ & 442.22 & -203.32 & 1087.76 & 0.179 \\
\hline \multicolumn{5}{|l|}{ Comorbidities } \\
\hline Hypertension & 92.04 & -431.93 & 616.02 & 0.731 \\
\hline Diabetes & 585.09 & -339.29 & 1509.46 & 0.215 \\
\hline Dyslipidemia & 165.12 & -457.74 & 787.97 & 0.603 \\
\hline Ischemic heart failure & 1446.58 & -1133.00 & 4026.16 & 0.272 \\
\hline Cardiac dysrhythmias & 837.32 & -409.88 & 2084.53 & 0.188 \\
\hline Heart failure & 1385.83 & -2310.40 & 5082.06 & 0.462 \\
\hline Stroke & 1486.30 & -851.96 & 3824.57 & 0.213 \\
\hline COPD & 633.28 & -215.27 & $|48| .83$ & 0.144 \\
\hline \multicolumn{5}{|l|}{ Other drugs } \\
\hline $\begin{array}{l}\text { Corticosteroids for } \\
\text { systemic use }\end{array}$ & 174.88 & -587.05 & 936.81 & 0.653 \\
\hline $\begin{array}{l}\text { Platelet aggregation } \\
\text { inhibitors }\end{array}$ & 248.20 & -344.83 & 841.22 & 0.412 \\
\hline $\begin{array}{l}\text { Vitamin } \mathrm{K} \text { antagonists } / \mathrm{Xa} \\
\text { factor inhibitors }\end{array}$ & 1857.97 & 147.27 & 3568.67 & 0.033 \\
\hline Analgesics & 1364.62 & 422.57 & 2306.67 & 0.005 \\
\hline Anticonvulsants & 918.01 & -210.56 & 2046.58 & 0.111 \\
\hline Antipsychotics/anxiolytics & 1566.89 & -366.80 & 3500.57 & 0.112 \\
\hline PPI & 419.11 & -104.70 & 942.92 & 0.117 \\
\hline \multicolumn{5}{|l|}{ MPR } \\
\hline$<40 \%$ & Reference & & & \\
\hline$\geq 40 \%<80 \%$ & -245.29 & -896.57 & 405.99 & 0.460 \\
\hline$\geq 80 \%$ & -122.35 & -669.74 & 425.04 & 0.661 \\
\hline \multicolumn{5}{|l|}{ Type of treatment } \\
\hline Osteo only [Reference]* & Reference & & & \\
\hline Osteo and $\mathrm{Ca} / \mathrm{VitD}$ & -1296.91 & -2155.90 & -437.93 & 0.003 \\
\hline
\end{tabular}

Note: *"Osteo only" refers to osteoporosis drugs only.

Abbreviations: $\mathrm{CCl}$, Charlson Comorbidity Index; $\mathrm{Cl}$, confidence interval; COPD, Chronic Obstructive Pulmonary Disease; MPR, Medication Possession Ratio; PPI, Proton Pump Inhibitor.

our data could not confirm whether this association was due to the type of hospitalization (ie, related or not to osteoporosis), since it was not explored in the cost analysis. It could be speculated that hospitalization costs represent standard costs (fixed cost related to recovery in hospital) and they relate to a slight variation when the total hospitalization cost is considered. However, hospitalization cost related to a fracture event includes the cost of the prosthesis, which represents an effective cost. In this sense, the prevention of subsequent fractures in patients with a recent fracture event may consistently decrease healthcare costs and, as shown in this study, the supplementation with calcium/vitamin D was identified as an additional factor for reduced annual healthcare expenditure per patient.

\section{Study Limitations}

The results of this study should be interpreted in the light of potential limitations. First, we analyzed the administrative database of five Italian LHUs; however, although LHUs were well distributed across the Italian territory we believe that caution should be reserved in extending our findings to the entire National health-assisted population over the age of 50 diagnosed with osteoporosis and the presence of a fracture, since this comprises subset of the general population and may be affected by regional differences. Second, cost analysis included costs retrieved from the public healthcare system and in a context of reimbursed services; thus, healthcare services provided by private health facilities or private hospitals were not detected. Third, differential access to healthcare was not evaluated. We do not consider this factor as having a relevant role in the present study; however, additional studies are warranted to explore this aspect further. Last, data on the use of pharmacological treatments were retrieved from medical prescription and dispensing so that the actual drug consumption was not available.

\section{Conclusion}

In the present investigation, we have demonstrated that osteoporotic patients aged 50 years and over receiving standard pharmacological osteoporosis treatment after a fracture had significantly lower healthcare costs, in particular for hospitalization, compared to untreated patients. Furthermore, standard treatment on top of calcium/vitamin D supplementation was also associated with lower mean annual healthcare costs compared to patients without supplementation.

\section{Abbreviations}

CCI, Charlson Comorbidity Index; CI, Confidence interval; DB, Databases; DRG, Diagnosis-related group; ICD9-CM, International Classification of Diseases, Ninth Revision, Clinical Modification; LHU, Local Health Unit; MPR, Medication Possession Ratio; NHS, National Health System; SD, Standard deviation.

\section{Ethics Approval and Informed Consent}

According to Italian law, ${ }^{25}$ this study has been notified to the local Ethics Committee of the LHU involved in the study. Informed consent was not required as we used encrypted retrospective information. 


\section{Data Sharing Statement}

Data are not available due to ethical issues.

\section{Acknowledgments}

We would like to thank all participants who took part in this study. This study was conducted on behalf of A Vercellone and E Nava (Department of Pharmacy, Local Health Unit Naples 3 South, Italy); F Ferrante, C Bianchi, S Crescenzi, P Filomena, M Folcatrelli (Department Diagnostic and Pharmacy - U.O.C. Pharmacy - Local Health Unit Frosinone, Italy); A Constantini (Hospital Pharmacy, "Spirito Santo Hospital", Pescara, Italy); C Cattaruzzi (Pharmaceutical Care Unit, ASUIUD, Udine, Italy).

\section{Author Contributions}

All authors contributed to data analysis, drafting and revising the article, gave final approval of the version to be published, and agree to be accountable for all aspects of the work.

\section{Funding}

This study was sponsored unconditionally by Abiogen Pharma S.p.A, Pisa, Italy.

\section{Disclosure}

The authors report no conflicts of interest in this work.

\section{References}

1. Rossini M, Adami S, Bertoldo F, et al. Guidelines for the diagnosis, prevention and management of osteoporosis. Reumatismo. 2016;68 (1):1-39. doi:10.4081/reumatismo.2016.870

2. Hernlund E, Svedbom A, Ivergård $\mathrm{M}$, et al. Osteoporosis in the European union: medical management, epidemiology and economic burden. A report prepared in collaboration with the International Osteoporosis Foundation (IOF) and the European Federation of Pharmaceutical Industry Associations (EFPIA). Arch Osteoporos. 2013;8:136. doi:10.1007/s11657-013-0136-1

3. Ministero della Salute - Salute della donna. Osteoporosi. Available from: http://www.salute.gov.it/portale/donna/dettaglioContenutiDonna jsp?lingua $=$ italiano\&id $=4491 \&$ are $=$ Salute $\% 20$ donna\&menu $=$ patologie. Accessed July 17, 2018.

4. IOF. Broken bones, broken lives: a roadmap to solve the fragility fracture crisis in Europe. Available from: http://share.iofbonehealth.org/EU6-Material/Reports/IOF\%20Report_EU.pdf. Accessed June 30, 2019.

5. Maravic M, Jouaneton B, Vainchtock A, Tochon V. Economic burden of osteoporosis in women: data from the 2008 French hospital database (PMSI). Clin Exp Rheumatol. 2012;30(2):222-227.

6. Degli Esposti L, Adami S, Iolascon G, et al. Il costo delle fratture da osteoporosi in italia. [Cost of osteoporotic fractures in Italy. Results from the BLOCK study (Bone loss and Osteoporosis: cost-of-illness knowledge)]. Farmacoeconomia e Percorsi Terapeutici. 2011;12 (3):99-105. doi:10.7175/fe.v12i3.125

7. Pavone V, Testa G, Giardina SMC, Vescio A, Restivo DA, Sessa G. Pharmacological therapy of Osteoporosis: a systematic current review of literature. Front Pharmacol. 2017;8. doi:10.3389/fphar.2017.00803.
8. Pazianas M, Abrahamsen B. Osteoporosis treatment: bisphosphonates reign to continue for a few more years, at least? Ann N Y Acad Sci. 2016;1376(1):5-13. doi:10.1111/nyas.13166

9. Kennel KA, Drake MT. Adverse effects of Bisphosphonates: implications for Osteoporosis management. Mayo Clin Proc. 2009;84 (7):632-638. doi:10.1016/S0025-6196(11)60752-0

10. Imam B, Aziz K, Khan M, Zubair T, Iqbal A. Role of bisphosphonates in postmenopausal women with Osteoporosis to prevent future Fractures: a literature review. Cureus. 2019;11(8):e5328. doi:10.7759/cureus.5328

11. Stepan JJ, Hruskova H, Kverka M. Update on menopausal hormone therapy for fracture prevention. Curr Osteoporos Rep. 2019;17:465-473. doi:10.1007/s11914-019-00549-3

12. Choi N-K, Solomon DH, Tsacogianis TN, Landon JE, Song HJ, Kim SC. Comparative safety and effectiveness of denosumab versus zoledronic acid in patients with Osteoporosis: a cohort study. $J$ Bone Miner Res. 2017;32(3):611-617. doi:10.1002/jbmr.3019

13. Lindsay R, Krege JH, Marin F, Jin L, Stepan JJ. Teriparatide for osteoporosis: importance of the full course. Osteoporos Int. 2016;27 (8):2395-2410. doi:10.1007/s00198-016-3534-6

14. Holick MF. Calcium and vitamin D. Diagnostics and therapeutics. Clin Lab Med. 2000;20(3):569-590. doi:10.1016/S0272-2712(18)30054-4

15. Holick MF, Binkley NC, Bischoff-Ferrari HA, et al. Evaluation, treatment, and prevention of vitamin D deficiency: an endocrine society clinical practice guideline. J Clin Endocrinol Metab. 2011;96(7):1911-1930. doi:10.1210/jc.2011-0385

16. Cândido FG, Bressan J. Vitamin D: link between osteoporosis, obesity, and diabetes? Int J Mol Sci. 2014;15(4):6569-6591. doi:10.3390/ ijms 15046569

17. Veldurthy V, Wei R, Oz L, Dhawan P, Jeon YH, Christakos S. Vitamin D, calcium homeostasis and aging. Bone Res. 2016;4 (1):1-7. doi:10.1038/boneres.2016.41

18. Bellavia D, Costa V, De Luca A, et al. Vitamin D level between calcium-phosphorus homeostasis and immune system: new perspective in Osteoporosis. Curr Osteoporos Rep. 2016. doi:10.1007/ s11914-016-0331-2

19. Eichner SF, Lloyd KB, Timpe EM. Comparing therapies for postmenopausal osteoporosis prevention and treatment. Ann Pharmacother. 2003;37(5):711-724. doi:10.1345/aph.1C246

20. Murad MH, Drake MT, Mullan RJ, et al. Clinical review. Comparative effectiveness of drug treatments to prevent fragility fractures: a systematic review and network meta-analysis. J Clin Endocrinol Metab. 2012;97 (6):1871-1880. doi:10.1210/jc.2011-3060

21. Freemantle N, Cooper C, Diez-Perez A, et al. Results of indirect and mixed treatment comparison of fracture efficacy for osteoporosis treatments: a meta-analysis. Osteoporos Int. 2013;24(1):209-217. doi:10.1007/s00198-012-2068-9

22. Hiligsmann M, Rabenda V, Gathon H-J, Ethgen O, Reginster J-Y. Potential Clinical and Economic impact of nonadherence with Osteoporosis medications. Calcif Tissue Int. 2010;86(3):202-210. doi:10.1007/s00223-009-9329-4.

23. Agenzia Italiana del Farmaco (AIFA). Nota 79 - Prescription of osteoporosis medications at risk of fragility fracture or subsequent fracture. Available from: http://www.gazzettaufficiale.it/eli/id/2015/ 05/20/15A03762/sg. Accessed January 31, 2020.

24. Degli Esposti L, Girardi A, Saragoni S, et al. Use of antiosteoporotic drugs and calcium/vitamin D in patients with fragility fractures: impact on re-fracture and mortality risk. Endocrine. 2019;64 (2):367-377. doi:10.1007/s12020-018-1824-9

25. Agenzia Italiana del Farmaco (AIFA). Guideline for the classification and conduction of the observational studies on medicines. 2010. Available from: http://www.agenziafarmaco.gov.it/sites/default/files/ 111.88758.1186138046156a0be.pdf. Accessed January 31, 2020.

26. Charlson ME, Pompei P, Ales KL, MacKenzie CR. A new method of classifying prognostic comorbidity in longitudinal studies: development and validation. J Chronic Dis. 1987;40(5):373-383. doi:10.1016/00219681(87)90171-8 
27. Hiligsmann M, Ben Sedrine W, Bruyère O, Evers SM, Rabenda V, Reginster J-Y. Cost-effectiveness of vitamin D and calcium supplementation in the treatment of elderly women and men with osteoporosis. Eur J Public Health. 2015;25(1):20-25. doi:10.1093/ eurpub/cku119
28. Hiligsmann M, Evers SM, Ben Sedrine W, et al. A systematic review of cost-effectiveness analyses of drugs for postmenopausal osteoporosis. Pharmacoeconomics. 2015;33(3):205-224. doi:10.1007/s40273-014$0231-1$

\section{Publish your work in this journal}

Nutrition and Dietary Supplements is an international, peerreviewed, open access journal focusing on research into nutritional requirements in health and disease, impact on metabolism and the identification and optimal use of dietary strategies and supplements necessary for normal growth and development. The journal welcomes submitted papers covering original research, basic science, clinical \& epidemiological studies, reviews and evaluations, guidelines, expert opinion and commentary, case reports and extended reports. The manuscript management system is completely online and includes a very quick and fair peer-review system, which is all easy to use. Visit http://www.dovepress.com/testimonials.php to read real quotes from published authors. 